\title{
Effect of liraglutide on blood pressure: a meta-analysis of liraglutide randomized controlled trials
}

\author{
Xu Zhao ${ }^{1} \mathbb{D}$, Kun Huang ${ }^{1}$, Meijie Zheng ${ }^{1}$ and Junting Duan ${ }^{1,2^{*}}$
}

\begin{abstract}
Background: Several clinical trials have studied the effects of glucagon-like peptide-1 receptor agonists (GLP-1RAs) on glycometabolism and cardiovascular risk factors since they were identified. Because of their cardiovascular benefits and efficacy in lowering glucose, GLP-1RAs are becoming increasingly important in clinical therapy for patients with or without pathoglycaemia. The aim of this study was to assess the effect of the GLP-1RA liraglutide on blood pressure based on randomised controlled trials (RCTs).

Methods: We searched PubMed for RCTs published from 2009 to 2018 comparing the effect of liraglutide on blood pressure with that of placebo in individuals with or without pathoglycaemia. RCTs in humans that included data describing blood pressure changes from baseline to the end of the trial were selected for inclusion in the meta-analysis.

Results: A total of 18 RCTs that enrolled 7616 individuals in the liraglutide group and 6046 individuals in the control group were included in this meta-analysis. Compared with placebo, liraglutide reduced systolic blood pressure (SBP) by $3.18 \mathrm{mmHg}(95 \% \mathrm{Cl}-4.32,-2.05), P<0.00001$, but had no significant effect on diastolic blood pressure (DBP). Subgroup analysis showed that the degree of reduction in SBP was associated with the dose of liraglutide but that significance disappeared when the intervention lasted over 1 year. Liraglutide $3.0 \mathrm{mg} / \mathrm{d}$ significantly reduced DBP by $1.46 \mathrm{mmHg}(95 \% \mathrm{Cl}-2.61,0.32), P=0.01$, but liraglutide $1.8 \mathrm{mg} / \mathrm{d}$ slightly increased DBP by $0.47 \mathrm{mmHg}(95 \% \mathrm{Cl} 0.11,0.83), \mathrm{P}=0.01$, compared with placebo.

Conclusions: This meta-analysis demonstrated that liraglutide significantly reduced SBP in individuals with or without pathoglycaemia compared with placebo, but the difference was no longer significant when the intervention lasted over 1 year. Moreover, the effect of liraglutide on blood pressure is associated with the dose. This finding may provide additional evidence for cardiovascular protection.
\end{abstract}

Keywords: Blood pressure, Cardiovascular risk factor, DBP, GLP-1RAs, Liraglutide, SBP

\section{Background}

Diabetes, a chronic and progressive metabolic disorder, is becoming a public health issue with a high prevalence and serious complications. The IDF (International Diabetes Federation) has estimated that there will be $59,200,000$ patients suffering from diabetes in 2035 [1]. Long-term hyperglycaemia leads to macrovascular and microvascular complications, which places a heavy

\footnotetext{
*Correspondence: duanjunting123@sina.com

${ }^{1}$ Civil Aviation General Hospital, Peking University, Beijing, China

${ }^{2}$ Endocrinology Department, Civil Aviation General Hospital, Chaoyang Road, Beijing, China
}

(c) The Author(s). 2019 Open Access This article is distributed under the terms of the Creative Commons Attribution 4.0 International License (http://creativecommons.org/licenses/by/4.0/), which permits unrestricted use, distribution, and reproduction in any medium, provided you give appropriate credit to the original author(s) and the source, provide a link to the Creative Commons license, and indicate if changes were made. The Creative Commons Public Domain Dedication waiver (http://creativecommons.org/publicdomain/zero/1.0/) applies to the data made available in this article, unless otherwise stated. burden on the health care system [2]. Diabetes, espeobesity, hypertension and dyslipidaemia. As a result, the American Diabetes Association (ADA) has recommended providing the components of diabetes care with the cardiovascular risk factors included [3]. Many large clinical studies have confirmed that blood pressure is one of the cardiovascular risk factors associated with diabetes, and strict blood pressure control could improve the cardiovascular prognosis of diabetic patients [4-7]. According to the ADVANCE study, a reduction of $5.6 \mathrm{mmHg}$ in $\mathrm{SBP}$ could significantly 
reduce the relative risk of death from cardiovascular disease by $18 \%$ [8].

GLP-1 is an endogenous incretin secreted by the intestines after eating and can promote the secretion of insulin, inhibit the secretion of glucagon, delay gastric emptying, and maintain the stability of blood glucose. Based on this activity, GLP-1RAs, which decrease glucose, the risk of hypoglycaemia and weight, have been developed and used in the treatment of type 2 diabetes patients. GLP-1RAs have been shown to have either superior or noninferior efficacy compared with other hypoglycaemic agents, such as metformin, thiazolidinediones (TZDs), insulin, sulfonylureas, and dipeptidyl peptidase-4 (DPP-4) inhibitors [9-16]. In addition, some studies confirmed that GLP-1RAs could significantly reduce weight, improve insulin sensitivity [17$22]$, and protect the function of $\beta$-cells [23, 24].

In recent years, an increasing number of studies have suggested that GLP-1RAs might produce further benefits with regard to cardiovascular factors [25, 26]. Initially, Viswanathan et al. found that adding exenatide treatment to existing insulin therapy in patients with type 2 diabetes could significantly reduce blood pressure by $9.2 \mathrm{mmHg}$ from baseline and that the reduction in blood pressure was independent of weight loss [27]. Since then, several research teams have conducted clinical studies investigating the efficacy of GLP-1RAs on blood pressure and other cardiovascular risk factors with different conclusions. Most studies concluded that GLP-1RAs could significantly reduce SBP and had a tendency to reduce DBP. Rosso et al. found that SBP significantly decreased by $14.7 \mathrm{mmHg}$ and that DBP significantly decreased by $9 \mathrm{mmHg}$ after 12 months of treatment with liraglutide, while fasting blood glucose, HbA1C, weight, waist circumference, and lipid levels also decreased significantly [28]. A study in nondiabetic obese adults found that SBP decreased by $5.7 \mathrm{mmHg}(1.2 \mathrm{mg} /$ day $), 5.6 \mathrm{mmHg}(1.8 \mathrm{mg} /$ day), $8.8 \mathrm{mmHg}(2.4 \mathrm{mg} /$ day $)$, and $6.9 \mathrm{mmHg}(3.0 \mathrm{mg} /$ day) compared with baseline after a 20 -week treatment with liraglutide and that DBP decreased by $1.2 \mathrm{mmHg}$, $1.8 \mathrm{mmHg}, 1.4 \mathrm{mmHg}$ and $2.9 \mathrm{mmHg}$, respectively [29]. The LEADER trial found that SBP decreased by $1.2 \mathrm{mmHg}$ and that DBP increased by $0.6 \mathrm{mmHg}$ in the liraglutide group after an intervention of 3.5 years [ 30 , 31]. A study in diabetic patients on peritoneal dialysis found that SBP decreased by $20-30 \mathrm{mmHg}$ after a 12 -month treatment with liraglutide, which might be associated with instability of the patients' volume load [32]. Therefore, exploring the influence of GLP-1RAs on blood pressure in a large population by collecting the data from all relevant trials is necessary.

Liraglutide is one of the long-acting GLP-1RAs marketed in Europe in 2009 and has better efficacy with regard to cardiovascular benefits and hyperglycaemia reduction [11, 33, 34]. This meta-analysis aimed to investigate the effect of liraglutide on blood pressure in individuals with abnormal glucose metabolism or metabolic syndrome by searching randomised controlled trials (RCTs).

\section{Methods}

The main objective of this meta-analysis was to assess the influence of liraglutide on blood pressure compared with that of placebo. Outcome measurements included SBP and DBP. We followed the methods specified in the Cochrane Handbook for Reviews on Interventions [35].

\section{Search strategy}

Eligible trials were identified by electronic and manual searches. Electronic searches were conducted by searching PubMed for articles dating from 2009 to 2018 using the terms "liraglutide" and "blood pressure". Manual searches were performed by reading the title, abstract and full text of relevant articles.

\section{Study selection}

After searching for candidate articles, further identification of these articles was based on the inclusion and exclusion criteria described below. The process was performed independently by two investigators.

The inclusion criteria were as follows: (a) published studies in humans; (b) randomised, placebo, parallel controlled trials; (c) outcome measurements included blood pressure.

The exclusion criteria were as follows: (a) participants suffered from severe liver or renal insufficiency and required replacement therapy; (b) cross-over control trials; or (c) using diuretics or drinking too much water, which might impact volume load.

\section{Data extraction}

The main data were extracted from each study after a full-text reading of each RCT included in the meta-analysis and included the following: (a) general information, such as the first author, title, year of publication, and sample size; (b) baseline characteristics of participants, such as age and duration of diabetes; (c) intervention measures, the duration of intervention and background therapy; and (d) changes in SBP and DBP from baseline to endpoint with the format of the mean (standard deviation).

\section{Quality assessment}

The quality assessment of these RCTs included in the meta-analysis was performed according to the Cochrane Collaboration's risk of bias assessment tools, which included six parts: selection bias (random sequence 
generation and allocation concealment), performance bias (blinding of participants and personnel), detection bias (blinding of outcome assessment), attrition bias (incomplete outcome data), reporting bias (selective reporting) and other bias [35].

\section{Data analysis}

Statistical analysis was conducted by Review Manager (RevMan version 5.3). We assessed the heterogeneity among RCTs by using the Cochrane $\mathrm{Q}$ test and $\mathrm{I}^{2}$ statistic. $\mathrm{I}^{2}$ values of less than $25 \%, 25-50 \%, 50-75 \%$ and more than $75 \%$ represent no heterogeneity, mild heterogeneity, moderate heterogeneity and considerable heterogeneity, respectively. We concentrated on the changes in SBP and DBP from baseline to endpoint with the format of the mean (standard deviation). If the article did not provide a calculated standard deviation, we imputed it via sample size, standard error, $95 \%$ confidence interval and $p$ value. The results of the meta-analysis were expressed as the weighted mean difference with 95\% confidence intervals. To increase the efficacy of the results, even if the heterogeneity was low or there was no heterogeneity, a random-effects model was selected.

\section{Compliance with ethics guidelines}

This article is based on previously conducted studies and does not contain any studies with human participants or animals performed by any of the authors.

\section{Results}

\section{Literature searches and study inclusion}

By searching PubMed, a total of 226 articles were screened. After excluding the articles that did not meet our inclusion criteria, 18 RCTs were included in the data analysis. All the included studies were randomised, double-blind, placebo, and parallel controlled trials. The study flow diagram is shown in Fig. 1. The characteristics of the RCTs included in the meta-analysis are shown in Table 1 and Table 2. Liraglutide was given at $0.6 \mathrm{mg}$ once daily in 2 trials [36, 37]. As liraglutide at $0.6 \mathrm{mg} / \mathrm{d}$ is rarely used in clinical practice, we removed these data from the comparison of liraglutide with placebo.

\section{Quality assessment}

We conducted a quality assessment of the 18 RCTs included in the meta-analysis according to the Cochrane Collaboration's risk of bias assessment tools. The characteristics at baseline of all 18 RCTs showed no significant difference between the liraglutide group and the

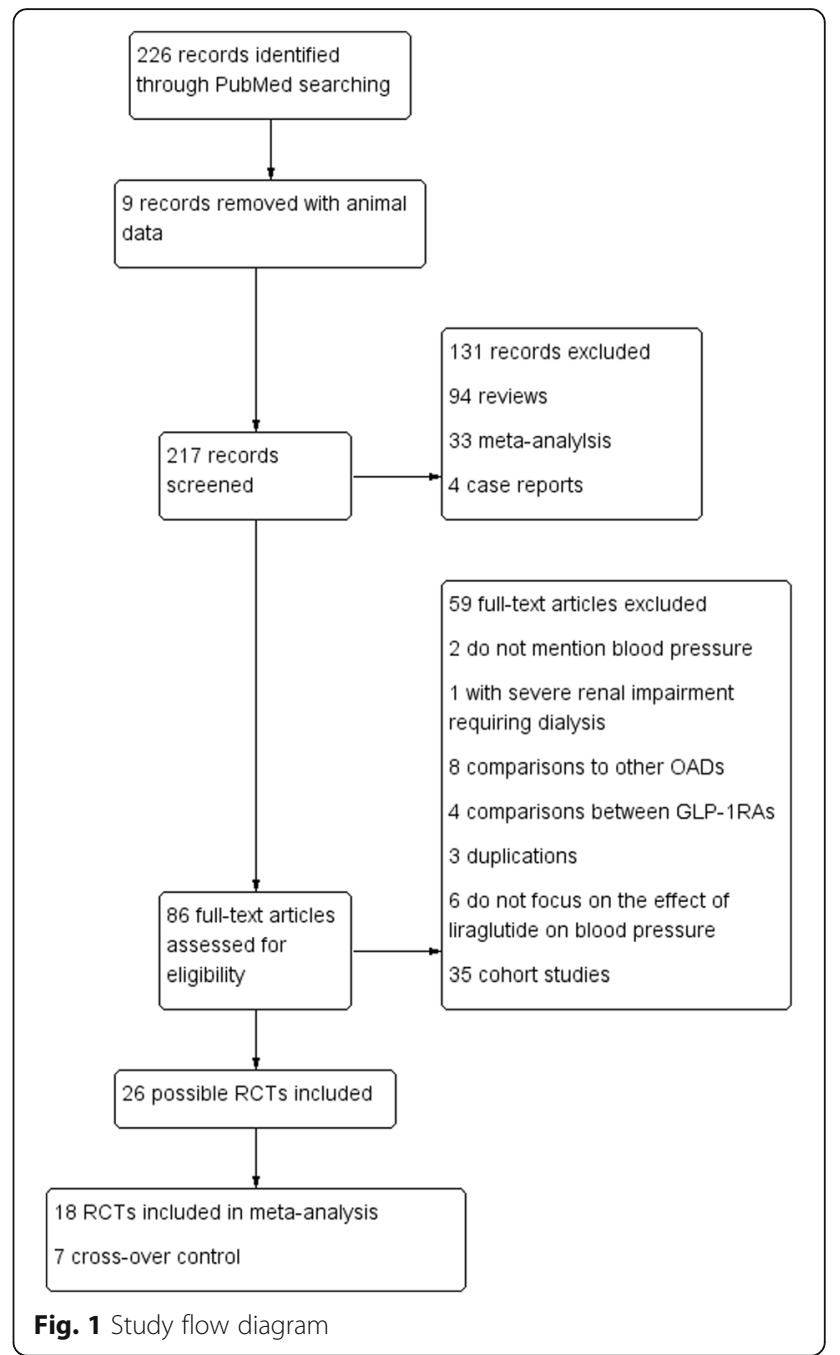

placebo group. Four RCTs did not provide clear information on random sequence generation and allocation concealment [38-41]. One RCT did not give the number of people who were lost to follow-up or withdrew and the reason [40]. All 18 RCTs were performed and assessed by blinding researchers and participants [29, 31, 36-51]. The risk of bias is shown in Fig. 2 and Fig. 3.

\section{SBP}

There were 7616 individuals in the liraglutide group and 6046 individuals in the placebo group included in the data analysis. Nine trials reported that liraglutide reduced SBP significantly compared with placebo [29, 31, 41-44, 46, 48, 49]. Eight trials did not show a significant difference in the reduction in SBP between liraglutide and placebo [36-40, 45, 47, 51], and 1 trial reported that liraglutide could slightly increase SBP without a clear significant difference [50]. The random- 


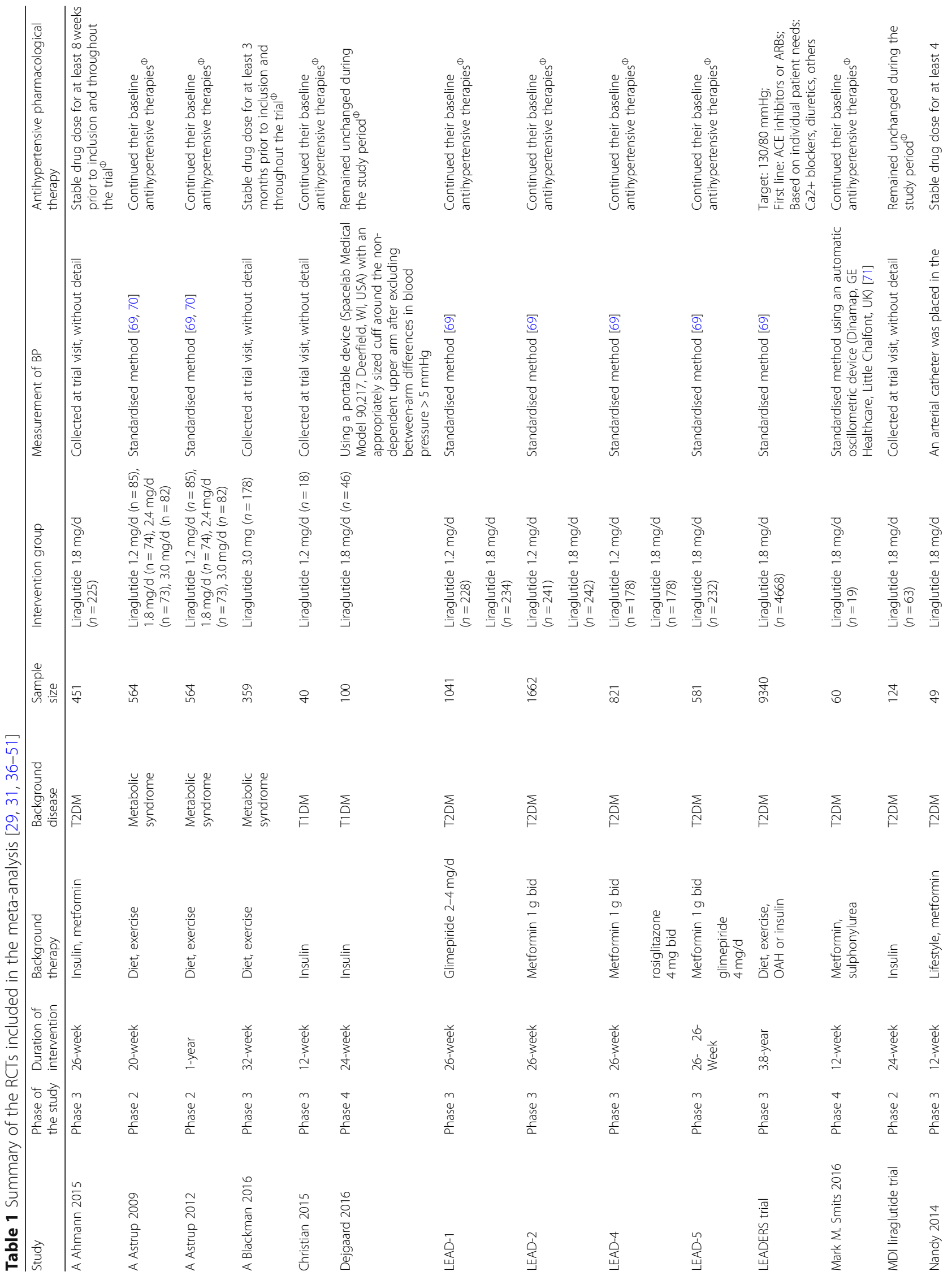




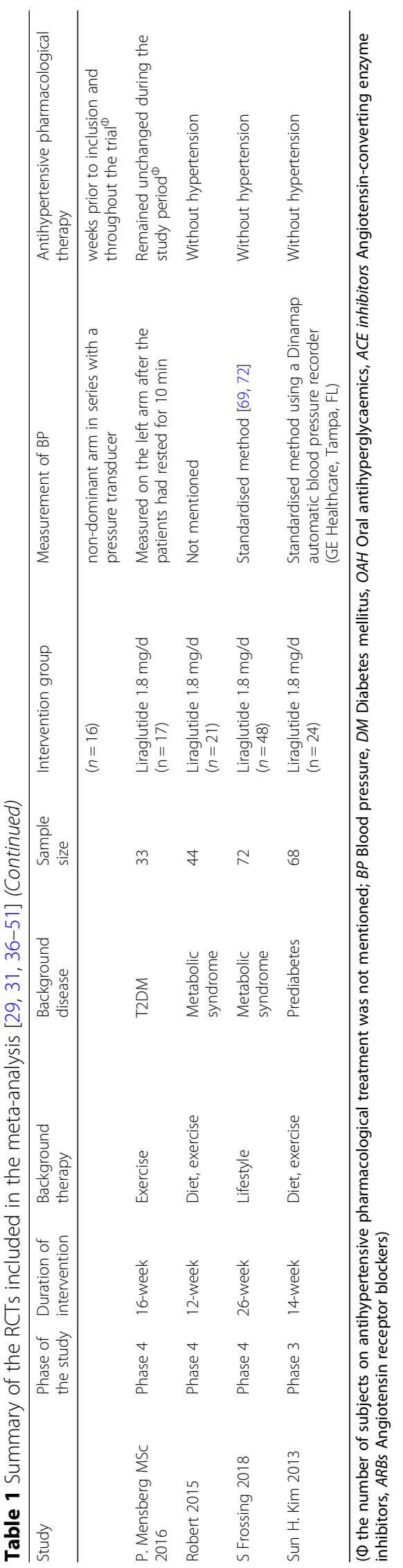


Table 2 Baseline Characteristics of trials included in the meta-analysis [29, 31, 36-51]

\begin{tabular}{|c|c|c|c|c|c|c|}
\hline Study & Age (years) & $\begin{array}{l}\text { Duration of diabetes } \\
\text { (years) }\end{array}$ & BMI $\left(\mathrm{kg} / \mathrm{m}^{2}\right)$ & Hypertension $(n, \%)$ & $\mathrm{SBP}(\mathrm{mmHg})$ & DBP $(\mathrm{mmHg}$ \\
\hline \multirow[t]{2}{*}{ A Ahmann 2015} & 1:59.3(9.2) & $\mathrm{l}: 12.1(7.1)$ & I:32.3(5.6) & Unavailable & Unavailable & Unavailable \\
\hline & P:57.5(11.1) & P:12.1(6.8) & P:32.2(5.7) & & & \\
\hline \multirow[t]{5}{*}{ A Astrup 2009} & |:47.2(9.7) & NA & $1: 34.8(2.6)^{\dagger}$ & Unavailable & $\mid: 127(13.1)^{\dagger}$ & $1: 79.7(9.1)^{\dagger}$ \\
\hline & $45.5(10.9)^{\ddagger}$ & & $35.0(2.6)^{\ddagger}$ & & $123(13.0)^{\ddagger}$ & $77.9(7.9)^{\ddagger}$ \\
\hline & $45.0(11.1)^{5}$ & & $35.0(2.8)^{5}$ & & $126(13.9)^{5}$ & $78.6(8.2)^{5}$ \\
\hline & $45.9(10.7)^{b}$ & & $34.8(2.8)^{b}$ & & $124(11.3)^{b}$ & $77.8(8.3)^{b}$ \\
\hline & P:45.9(10.3) & & P:34.9(2.8) & & $P: 124(11.1)$ & P:76.8(8.5) \\
\hline \multirow[t]{5}{*}{ A Astrup 2012} & I:47.2(9.7) & NA & $1: 34.8(2.6)^{\dagger}$ & Unavailable & $\mathrm{l}: 127(13.1)^{\dagger}$ & $1: 79.7(9.1)^{\dagger}$ \\
\hline & $45.5(10.9)^{\ddagger}$ & & $35.0(2.6)^{\ddagger}$ & & $123(13.0)^{\ddagger}$ & $77.9(7.9)^{\ddagger}$ \\
\hline & $45.0(11.1)^{\S}$ & & $35.0(2.8)^{5}$ & & $126(13.9)^{5}$ & $78.6(8.2)^{5}$ \\
\hline & $45.9(10.7)^{b}$ & & $34.8(2.8)^{b}$ & & $124(11.3)^{b}$ & $77.8(8.3)^{b}$ \\
\hline & P:45.9(10.3) & & P:34.9(2.8) & & P:124(11.1) & P:76.8(8.5) \\
\hline \multirow[t]{2}{*}{ A Blackman 2016} & |:48.6 (9.9) & NA & 1:38.9(6.4) & |:75,41.7\% & |:125.8(11.5) & $\mid: 81.2(7.6)$ \\
\hline & P:48.4(9.5) & & P:39.4(7.4) & P:77,43\% & P:127.1(12.3) & P:82.2(8.8) \\
\hline \multirow[t]{2}{*}{ Christian 2015} & |:39.5(2.7) & |:18.33(2.0) & |:24.17(0.64) & Unavailable & $\mid: 129.4(2.5)$ & $\mid: 75.5(1.7)$ \\
\hline & P:36.1(1.6) & P:19.56(1.6) & $P: 22.75(0.41)$ & & P:127.3(2.2) & P:72.5(1.4) \\
\hline \multirow[t]{2}{*}{ Dejgaard 2016} & |:47(13) & l:20(12) & |:30.3(3.5) & Unavailable & l:131(15) & $1: 82(9)$ \\
\hline & P:49(12) & $P: 25(12)$ & P:29.8(3.1) & & P:130(16) & $P: 81(8)$ \\
\hline \multirow[t]{3}{*}{ LEAD-1 } & $1: 57.7(9)^{+}$ & I:6.7(4.0,10.7) ${ }^{*^{+}}$ & $1: 29.8(5.1)^{\dagger}$ & $\mid: 155,68 \%{ }^{\dagger}$ & |:133(15) & Unavailable \\
\hline & $55.6(10)^{\ddagger}$ & $6.5(3.7,10.5)^{* \neq}$ & $30.0(5.1)^{\ddagger}$ & $163,69.7 \%^{\ddagger}$ & $132(16)^{\ddagger}$ & \\
\hline & P:54.7(10) & $P: 6.5(4.5,10.6)^{*}$ & P:30.3(5.4) & P:74,64.9\% & P:131(15.3) & \\
\hline \multirow[t]{3}{*}{ LEAD-2 } & 1:57.0(9) ${ }^{+}$ & $1: 7.0(5)^{\dagger}$ & $1: 31.1(4.8)^{\dagger}$ & Unavailable & I:132(14) ${ }^{\dagger}$ & $1: 80(10)^{\dagger}$ \\
\hline & $57.0(9)^{\ddagger}$ & $8.0(5)^{\ddagger}$ & $30.9(4.6)^{\ddagger}$ & & $131(14)^{\ddagger}$ & $79(8)^{\ddagger}$ \\
\hline & P:56.0(9) & $\mathrm{P}: 8.0(6)$ & $P: 31.6(4.4)$ & & P:135(16) & $\mathrm{P}: 81(9)$ \\
\hline \multirow[t]{3}{*}{ LEAD-4 } & 1:55.0(10) ${ }^{\dagger}$ & $1: 9.0(6)^{\dagger}$ & $1: 33.2(5.4)^{\dagger}$ & Unavailable & $\mathrm{l}: 129(14.8)^{\dagger}$ & l:75.8(9.0) \\
\hline & $55.0(11)^{\ddagger}$ & $9.0(6)^{\ddagger}$ & $33.5(5.1)^{\ddagger}$ & & $126(14.2)^{\ddagger}$ & $75.2(8.4)^{\ddagger}$ \\
\hline & P:55.0(10) & $P: 9.0(6)$ & P:33.9(5.2) & & $P: 128(14.5)$ & P:76.2(9.2) \\
\hline \multirow[t]{2}{*}{ LEAD-5 } & 1:57.6(9.5) & $1: 9.2(5.8)$ & l:30.4(5.3) & Unavailable & l:135(15.0) & |:80.8(9.1) \\
\hline & P:57.5(9.6) & P:9.4(6.2) & P:31.3(5.0) & & P:133(14.0) & P:80.4(9.3) \\
\hline \multirow[t]{2}{*}{ LEADERS trial } & 1:64.2(7.2) & l:12.8(8.0) & l:32.5(6.3) & Unavailable & |:135.9(17.8) & $1: 77.2(10.3)$ \\
\hline & P:64.4(7.2) & P:12.9(8.1) & $P: 32.5(6.3)$ & & P:135.9(17.7) & $P: 77.0(10.1)$ \\
\hline \multirow[t]{2}{*}{ Mark M. Smits 2016} & |:62.8(6.9) & Unavailable & |:32.0(30.9-35.9)* & Unavailable & l:136.6(17.0) & |:77.0(5.4) \\
\hline & P:62.8(6.9) & & P:30.8(28.9-31.5)* & & P:137.6(14.9) & P:76.4(6.8) \\
\hline \multirow[t]{2}{*}{ MDI liraglutide trial } & 1:63.7(8.2) & I:17.3(7.6) & 1:33.7(4.3) & Unavailable & I:137.9(16.8) & ::73.5(12.7) \\
\hline & P:63.5(7.7) & P:17.0(8.1) & P:33.5(4.0) & & $P: 133.7(13.7)$ & P:74.9(8.5) \\
\hline \multirow[t]{2}{*}{ Nandy 2014} & 1:57.7(9) & : :5.3(4.1) & 1:32.7(4.5) & Unavailable & Unavailable & Unavailable \\
\hline & P:60.3(7.3) & P:8.4(4.6) & P:31.6(4.2) & & & \\
\hline \multirow[t]{2}{*}{ P. Mensberg MSc 2016} & 1:56.5(9) & $\mathrm{l}: 6(5.2)$ & |:32.5(3.7) & Unavailable & l:136.4(11.0) & $\mid: 84.1(7.0)$ \\
\hline & P:55.6(12) & P:3.7(3.3) & P:32.4(5.2) & & $P: 136.2(8.9)$ & $\mathrm{P}: 82.1(7.0)$ \\
\hline \multirow[t]{2}{*}{ Robert 2015} & 1:34(9) & NA & l:36.15(3.84) & $0,0 \%$ & $\mathrm{l}: 130(15)$ & $1: 76(11)$ \\
\hline & $P: 34(9)$ & & P:35.74(4.55) & & P:133(17) & $P: 78(10)$ \\
\hline \multirow[t]{2}{*}{ S Frossing 2018} & $\mid: 29.9(6.1)$ & NA & |:33.3(5.1) & $0,0 \%$ & l:123(9) & 1:79(8) \\
\hline & P:29.9(6.1) & & P:33.3(4.6) & & P:124(9) & $P: 80(7)$ \\
\hline \multirow[t]{2}{*}{ Sun H. Kim 2013} & 1:58.0(7) & NA & |:31.9(2.7) & $0,0 \%$ & $\mid: 127(10)$ & l:76(9) \\
\hline & P:58.0(8) & & P:31.9(3.5) & & $P: 119(14)$ & P:75(8) \\
\hline
\end{tabular}

(Abbreviations: BMI Body mass index, SBP Systolic blood pressure, DBP Diastolic blood pressure, NA Not applicable, I Intervention group, $P$ Placebo group, age and the duration of diabetes were expressed as mean(SD) unless otherwise noted, * median (25th and 75th percentile); † liraglutide $1.2 \mathrm{mg} / \mathrm{d}, \neq$ liraglutide $1.8 \mathrm{mg} / \mathrm{d}, \S$ liraglutide $2.4 \mathrm{mg} / \mathrm{d}$, b liraglutide $3.0 \mathrm{mg} / \mathrm{d}$ )) 


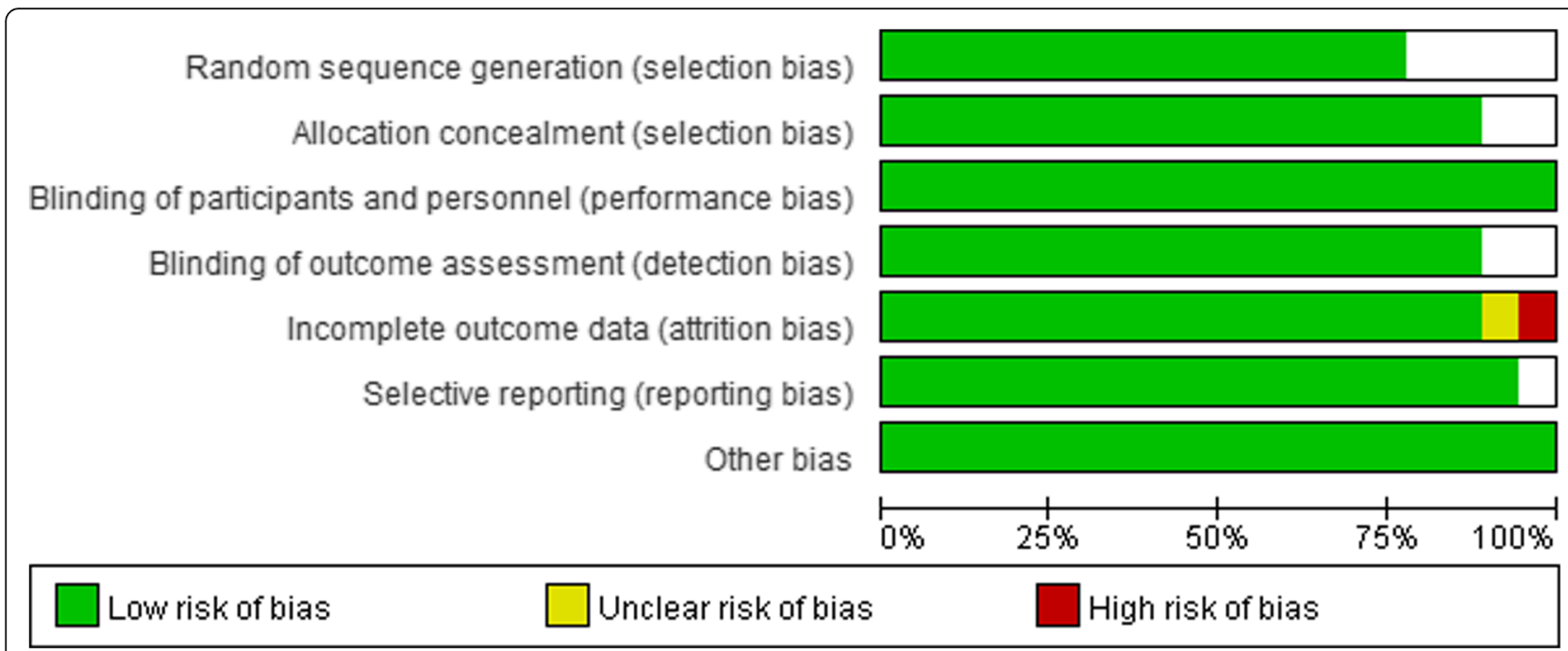

Fig. 2 Risk of bias graph

effects model showed that liraglutide significantly reduced SBP compared with placebo. The mean difference was $3.18 \mathrm{mmHg}\left(-4.32\right.$ to $-2.05, \mathrm{I}^{2}=55 \%, P<$ 0.00001 ) (Fig. 4). The $\mathrm{I}^{2}$ values suggested moderate heterogeneity, which might be related to the demographic characteristics, background therapy, dose of liraglutide and duration of intervention in each study.

We conducted subgroup analysis defined by the dose of liraglutide. Liraglutide significantly reduced SBP by $2.23 \mathrm{mmHg} \quad(-3.91$ to $-0.54, \quad \mathrm{I} 2=33 \%, \quad \mathrm{P}<0.00001)$, $2.88 \mathrm{mmHg}\left(-4.13\right.$ to $\left.-1.62, \mathrm{I}^{2}=51 \%, \mathrm{P}<0.00001\right)$, $5.01 \mathrm{mmHg}\left(-7.58\right.$ to $\left.-2.45, \mathrm{I}^{2}=0 \%, P=0.0001\right)$, and $3.67 \mathrm{mmHg}$ ( -5.35 to $\left.-1.99, \mathrm{I}^{2}=0 \%, P<0.0001\right)$ compared with placebo in the liraglutide $1.2 \mathrm{mg} / \mathrm{d}$ stratification, $1.8 \mathrm{mg} / \mathrm{d}$ stratification, $2.4 \mathrm{mg} / \mathrm{d}$ stratification and $3.0 \mathrm{mg} / \mathrm{d}$ stratification, respectively (Fig. 5).

In addition, we conducted subgroup analysis defined by the duration of intervention. Subgroup analysis did not show a significant difference in reduction in SBP between the liraglutide group with a more than 1-year duration of intervention and the placebo group. The mean difference was $-1.78 \mathrm{mmHg}(-3.69$ to $0.14, P=0.07$, $\mathrm{I}^{2=} 47 \%$ ). Compared with the placebo group, the liraglutide group with a less than 1-year duration of intervention showed a significant reduction in SBP of 3.44 mmHg ( -4.63 to $-2.25, P<0.00001, \mathrm{I}^{2}=37 \%$ ) (Fig. 6).

\section{DBP}

Fourteen trials reported changes in DBP from baseline to endpoint $[29,31,38-45,48-51]$. We performed a random-effects meta-analysis with 5952 individuals assigned to liraglutide and 5482 individuals assigned to placebo. No significant difference was found in the reduction in DBP between liraglutide and placebo. The mean difference was $0.05 \mathrm{mmHg}$ ( -0.67 to $0.57, P=0.87, \mathrm{I}^{2}=19 \%$ ) (Fig. 7).

We conducted subgroup analysis defined by the dose of liraglutide. Liraglutide $3.0 \mathrm{mg} / \mathrm{d}$ significantly reduced DBP by $1.46 \mathrm{mmHg}\left(-2.61\right.$ to $-0.32, \mathrm{I}^{2}=0 \%$, $P=0.01)$ compared with placebo. However, liraglutide $1.8 \mathrm{mg} / \mathrm{d}$ slightly increased DBP by $0.47 \mathrm{mmHg}(0.11$ to $0.83, \mathrm{I}^{2}=0 \%, \mathrm{P}=0.01$ ) (Fig. 8 ). In addition, we conducted subgroup analysis defined by the duration of intervention, which showed that liraglutide did not significantly reduce DBP compared with placebo, whether the duration of intervention was more than or less than 1 year (Fig. 9).

\section{Discussion}

\section{Explanation for findings}

As liraglutide $0.6 \mathrm{mg} / \mathrm{d}$ subcutaneous injection was well tolerated and rarely used in clinical practice, we eliminated the data on liraglutide $0.6 \mathrm{mg} / \mathrm{d}$. The random-effects model showed a significant difference in reduction in SBP between liraglutide and placebo by $-3.18 \mathrm{mmHg}$ but no significant difference in reduction in DBP. Subgroup analysis showed that the degree of reduction in SBP was associated with the dose of liraglutide and the duration of intervention. The larger the dose of liraglutide was, the greater the reduction in SBP. However, the degree of reduction in SBP declined when the dose of liraglutide was $3.0 \mathrm{mg} / \mathrm{d}$. Subgroup meta-analysis showed that short-term intervention with liraglutide (less than 1 year) could reduce SBP significantly compared with placebo but that the difference in reduction would disappear when the intervention lasted over 1 year. The 


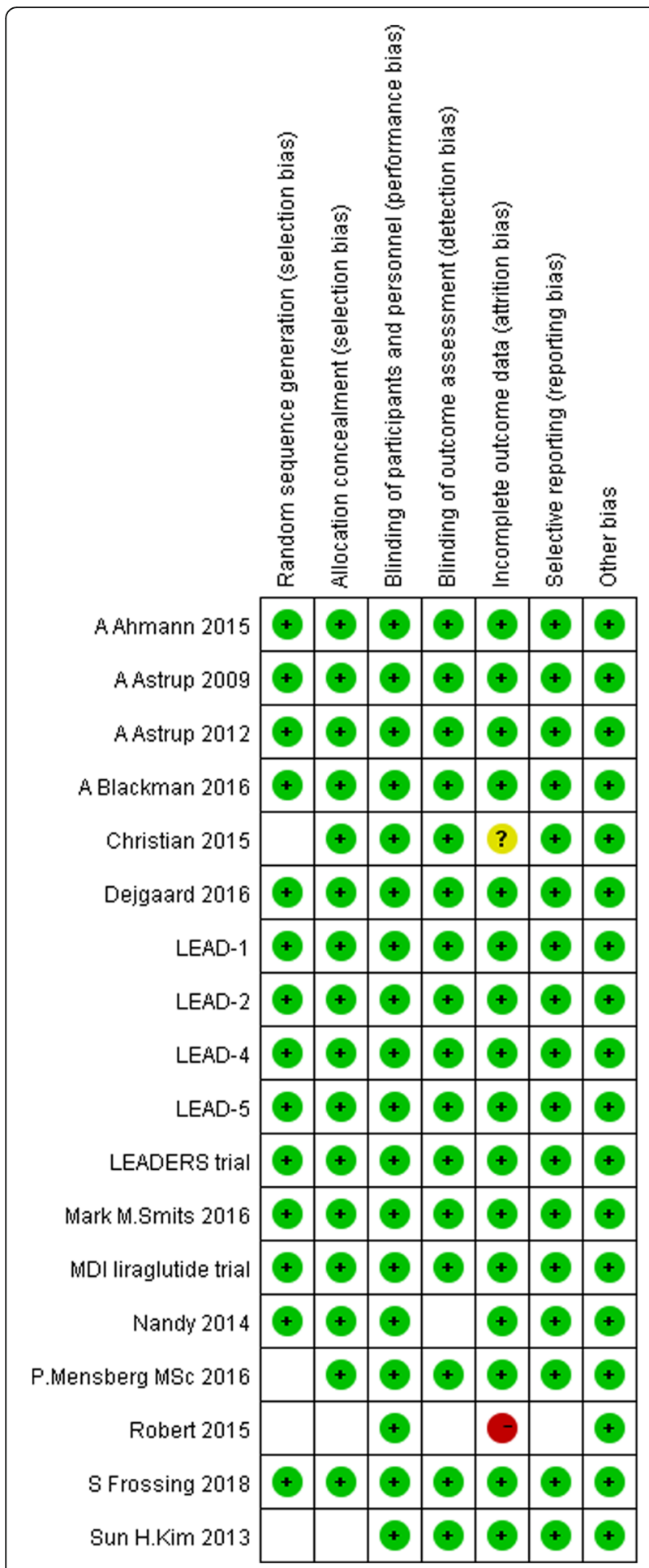

Fig. 3 Risk of bias summary (+, low risk of bias; -, high risk of bias;?, unknown risk of bias)

mechanism underlying this phenomenon was not clear. However, there were only 2 trials with a more than 1-year duration of intervention, so the results might be related to the adherence to the medication, or compliance of the participants. In addition, there were limited trials in the liraglutide $2.4 \mathrm{mg} / \mathrm{d}$ stratification and the liraglutide $3.0 \mathrm{mg} / \mathrm{d}$ stratification. Thus, additional long-term and large-dosage clinical trials are needed to probe the further efficacy of liraglutide on blood pressure.

\section{Assessment of quality of included studies}

This meta-analysis included 18 RCTs. All of the included trials were randomised, double-blind, placebocontrolled, parallel trials. To improve the grade of evidence, we excluded cross-over controlled trials from comparisons between liraglutide and placebo. After quality assessment, the bias risk of the included trials was relatively low.

The GLP-1RA liraglutide, as a new method of antidiabetic therapy, has been shown by a considerable number of trials to demonstrate efficacy in lowering fasting blood glucose, postprandial blood glucose, and weight. Increasing numbers of clinical studies have shown its cardiovascular benefits, providing further evidence for clinical use of liraglutide beyond antihyperglycaemia [8-14, 17-20, 27, 28]. In recent years, some researchers performed meta-analyses to compare liraglutide and other antihyperglycaemic agents, such as sulfonylureas, insulin, TZDs, DPP-4 inhibitors and other GLP-1RAs, demonstrating different effects in lowering $\mathrm{HbA} 1 \mathrm{C} /$ fasting plasma glucose/postprandial plasma glucose, adverse events, and improvement in insulin resistance, weight loss and the risk of hypoglycaemia [25, 26, 34, 52-57]. However, the influence of liraglutide on blood pressure was still uncertain.

Hypertension is highly correlated with diabetes but remains underrecognised and undertreated in the diabetic and the general population. The UK prospective diabetes study found that strict blood pressure control in patients with hypertension and type 2 diabetes substantially reduced the risk of death and complications due to diabetes [58]. In the active-treatment arm of the ADVANCE study, a decrease in blood pressure of 5.6/ $2.2 \mathrm{mmHg}$ in high-risk patients with T2DM reduced the rate of renal adverse events by $21 \%$ [59]. Our meta-analysis showed that SBP was reduced by approximately $5 \mathrm{mmHg}$, which may be a cardioprotective benefit. A study based on healthy adults found that plasma levels of fasting GLP-1 are significantly and positively related to the blood pressure indices assessed [60]. The increase in GLP-1 levels could be a compensatory response to individual $\mathrm{BP}$ elevations. The possible mechanisms by which GLP-1 reduces BP are vasodilatory properties [61] and improvement of endothelial function [62,63]. In addition, there is some 


\begin{tabular}{|c|c|c|c|c|c|c|c|c|c|c|c|c|}
\hline \multirow[b]{2}{*}{ Study or Subgroup } & \multicolumn{3}{|c|}{ liraglutide } & \multicolumn{2}{|c|}{ placebo } & \multirow[b]{2}{*}{ Total } & \multirow[b]{2}{*}{ Weight } & \multirow{2}{*}{$\begin{array}{l}\text { Mean Difference } \\
\text { IV, Random, } 95 \% \mathrm{Cl}\end{array}$} & \multirow{2}{*}{\multicolumn{3}{|c|}{$\begin{array}{c}\text { Mean Difference } \\
\text { IV. Random, } 95 \% \mathrm{Cl}\end{array}$}} & \\
\hline & Mean & SD & Total & Mean & $\mathrm{SD}$ & & & & & & & \\
\hline A.Ahmann 2015 & -5.78 & 13.15 & 225 & -0.76 & 13.15 & 225 & $8.3 \%$ & $-5.02[-7.45,-2.59]$ & & - & & \\
\hline A.Astrup 2009 & -6.75 & 12.2 & 368 & -4 & 11.97 & 98 & $7.7 \%$ & $-2.75[-5.43,-0.07]$ & & $\rightarrow$ & & \\
\hline A Astrup 2012 & -5.03 & 14 & 368 & -1.6 & 14 & 98 & $6.7 \%$ & $-3.43[-6.55,-0.31]$ & & $\rightarrow$ & & \\
\hline A Blackman 2016 & -4.1 & 10.6 & 178 & 0 & 10.6 & 179 & $8.9 \%$ & $-4.10[-6.30,-1.90]$ & & $\rightarrow$ & & \\
\hline Christian 2015 & -2.3 & 7.81 & 18 & 0.9 & 7.81 & 18 & $3.6 \%$ & $-3.20[-8.30,1.90]$ & & & & \\
\hline Dejgaard 2016 & -6 & 15.31 & 50 & -1.8 & 15.31 & 50 & $2.8 \%$ & $-4.20[-10.20,1.80]$ & & & & \\
\hline LEAD-1 & -2.7 & 12.89 & 462 & -2.3 & 12.4 & 114 & $8.0 \%$ & $-0.40[-2.96,2.16]$ & & - & & \\
\hline LEAD-2 & -2.7 & 13.04 & 483 & -1.8 & 12.5 & 122 & $8.1 \%$ & $-0.90[-3.40,1.60]$ & & - & & \\
\hline LEAD-4 & -6.15 & 14.89 & 356 & -1.1 & 15.2 & 177 & $7.6 \%$ & $-5.05[-7.77,-2.33]$ & & - & & \\
\hline LEAD-5 & -3.97 & 19.73 & 232 & -1.44 & 16.8 & 115 & $5.1 \%$ & $-2.53[-6.51,1.45]$ & & 6 & & \\
\hline LEADERS trial & -1.33 & 17.26 & 4668 & -0.13 & 17.26 & 4672 & $12.8 \%$ & $-1.20[-1.90,-0.50]$ & & $=$ & & \\
\hline Mark M.Smits 2016 & -9.1 & 14.08 & 19 & 2.4 & 14.08 & 17 & $1.4 \%$ & $-11.50[-20.71,-2.29]$ & & & & \\
\hline MDI liraglutide trial & -5.69 & 13.38 & 63 & 1.98 & 13.32 & 59 & $4.0 \%$ & $-7.67[-12.41,-2.93]$ & & - & & \\
\hline Nandy 2014 & -4.6 & 9.6 & 16 & -4.8 & 9.73 & 14 & $2.2 \%$ & $0.20[-6.74,7.14]$ & & & & \\
\hline P.Mensberg MSc 2016 & -5.4 & 7.4 & 17 & -0.6 & 11.1 & 16 & $2.5 \%$ & $-4.80[-11.28,1.68]$ & & & & \\
\hline Robert 2015 & -7 & 14.76 & 21 & 2 & 15.74 & 21 & $1.4 \%$ & $-9.00[-18.23,0.23]$ & & & & \\
\hline S Frossing 2018 & -3.12 & 7.43 & 48 & -1.96 & 7.43 & 24 & $5.6 \%$ & $-1.16[-4.80,2.48]$ & & & & \\
\hline Sun H.Kim 2013 & -8.1 & 10.54 & 24 & -2.6 & 8.59 & 27 & $3.4 \%$ & $-5.50[-10.82,-0.18]$ & & & & \\
\hline Total $(95 \% \mathrm{Cl})$ & & & 7616 & & & 6046 & $100.0 \%$ & $-3.18[-4.32,-2.05]$ & & $\bullet$ & & \\
\hline $\begin{array}{l}\text { Heterogeneity: } \operatorname{Tau}^{2}=2 \\
\text { Test for overall effect: } Z\end{array}$ & $\begin{array}{l}50 ; \mathrm{Chi}^{2}= \\
5.49(\mathrm{P}\end{array}$ & $\begin{array}{l}=38.13 \\
<0.000\end{array}$ & $\begin{array}{l}d f=17 \\
011)\end{array}$ & $(P=0$. & $.002) ; 1^{2}$ & $=55 \%$ & & & -20 & $-10 \quad 0$ & $\begin{array}{l}0 \\
\text { placebo }\end{array}$ & 20 \\
\hline
\end{tabular}

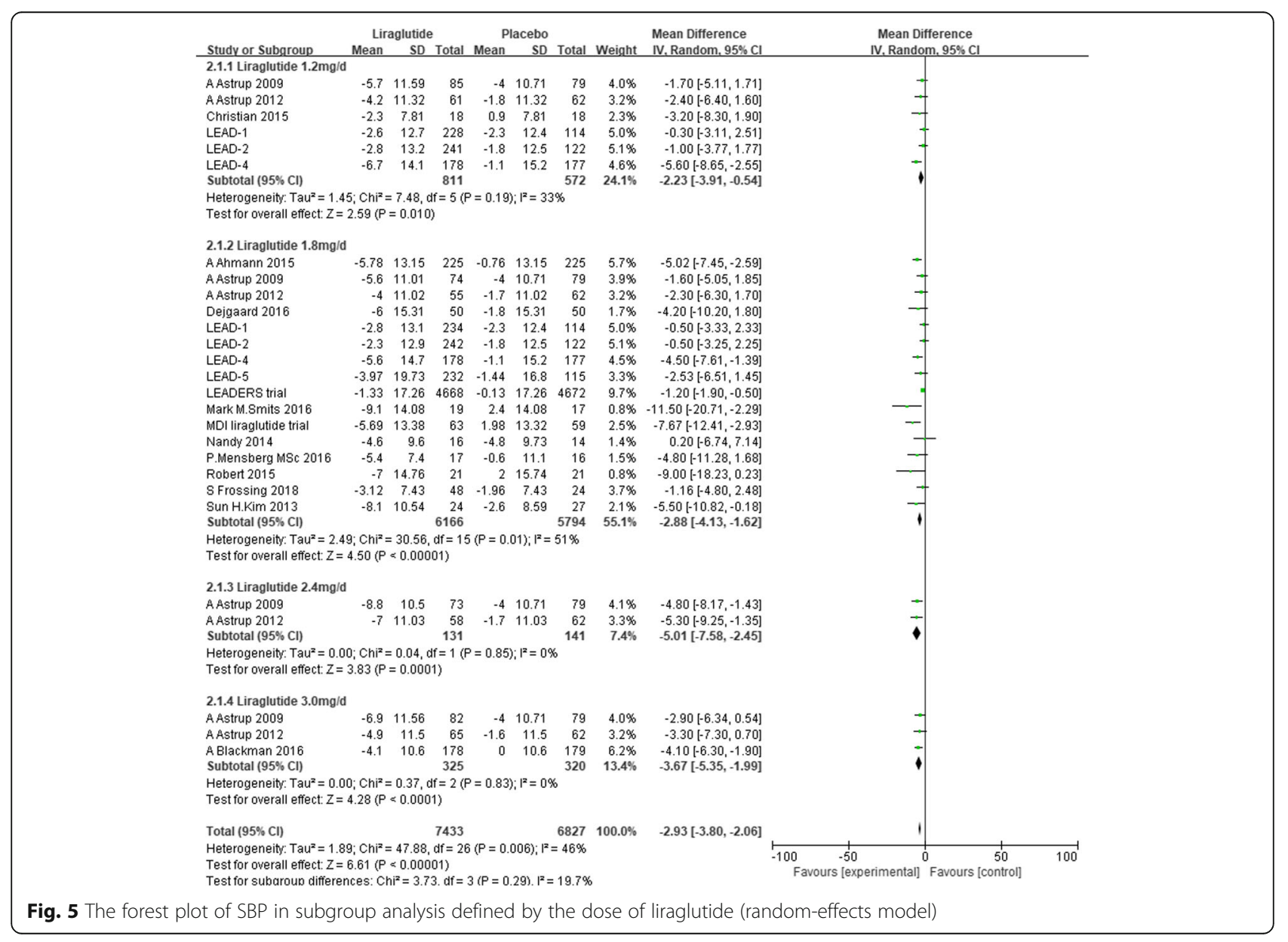




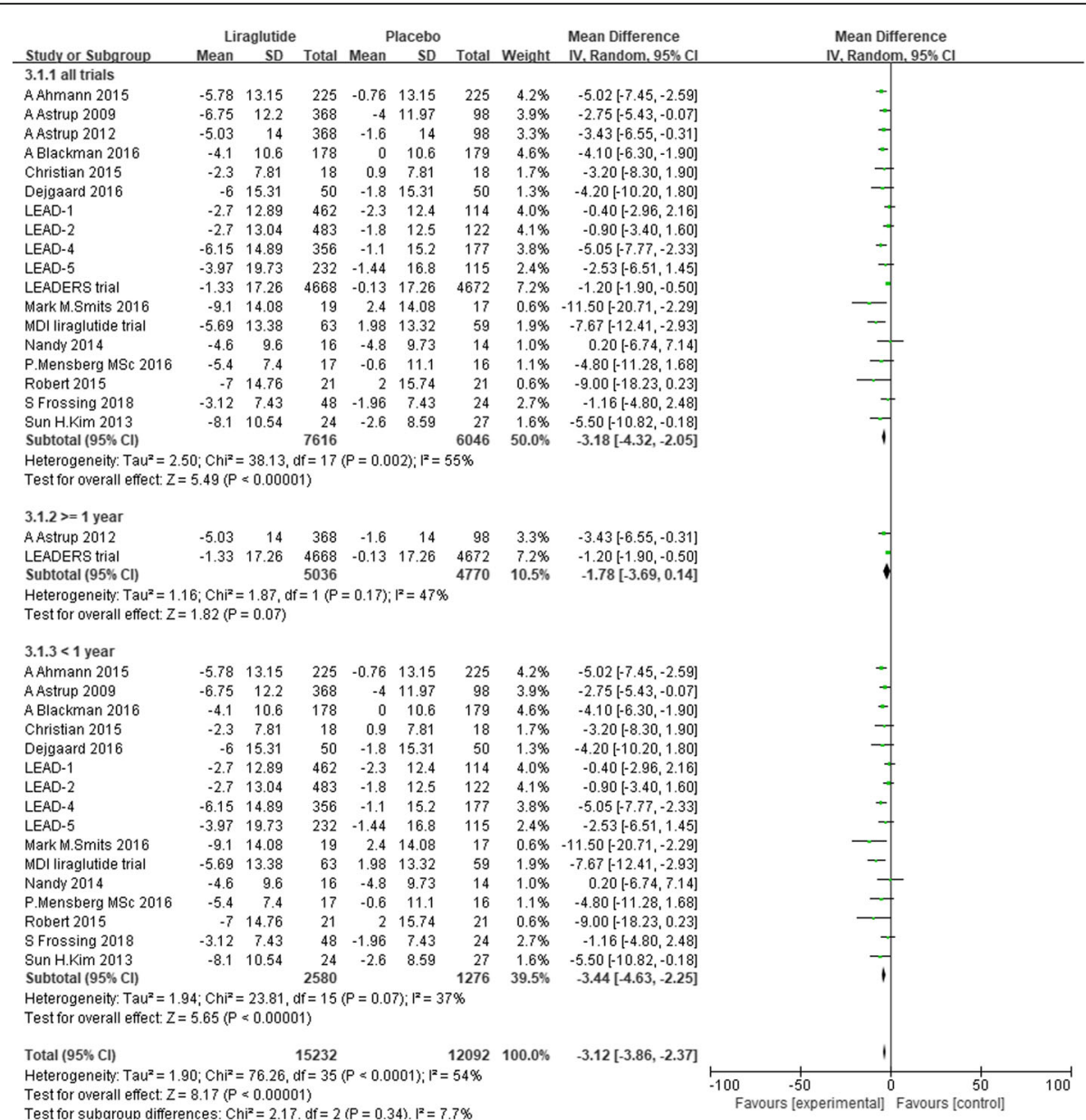

Fig. 6 The forest plot of SBP in subgroup analysis defined by the duration of intervention (random-effects model)

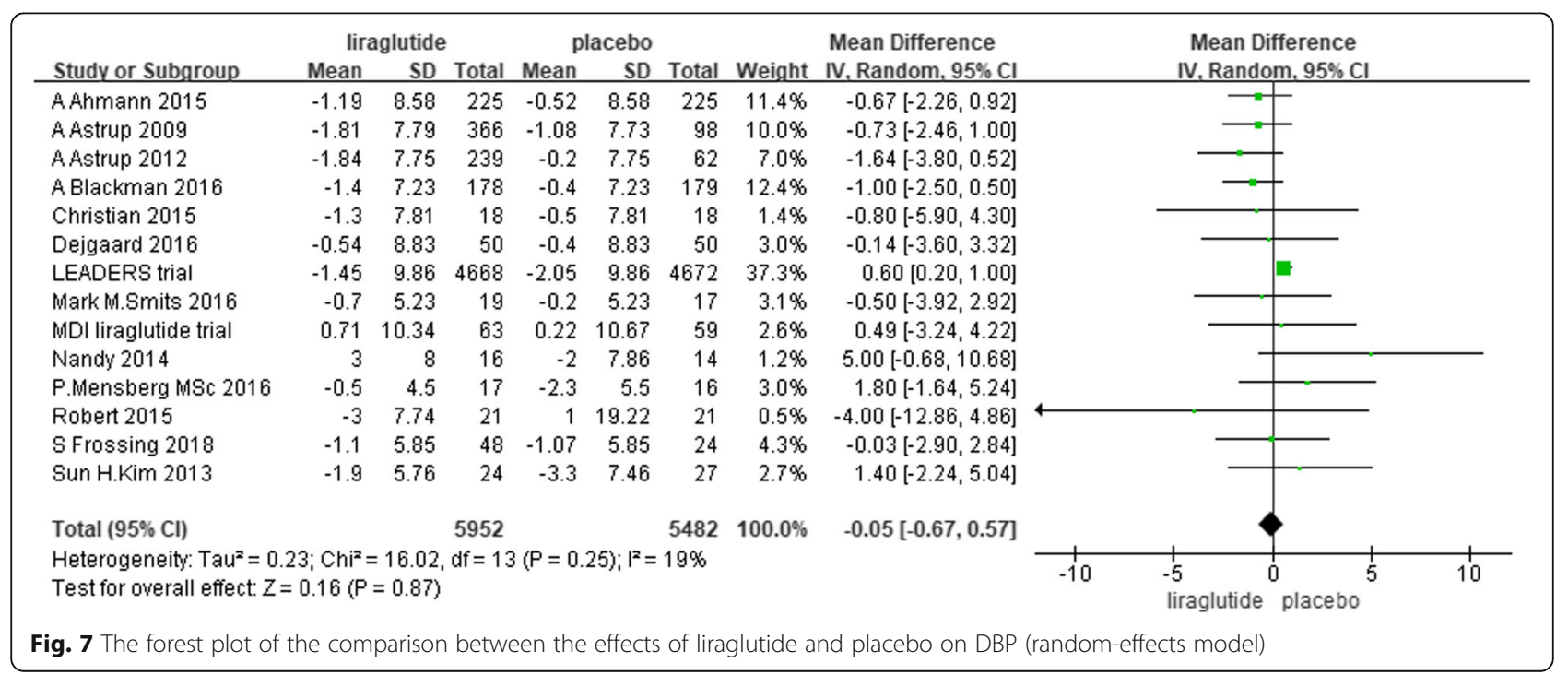




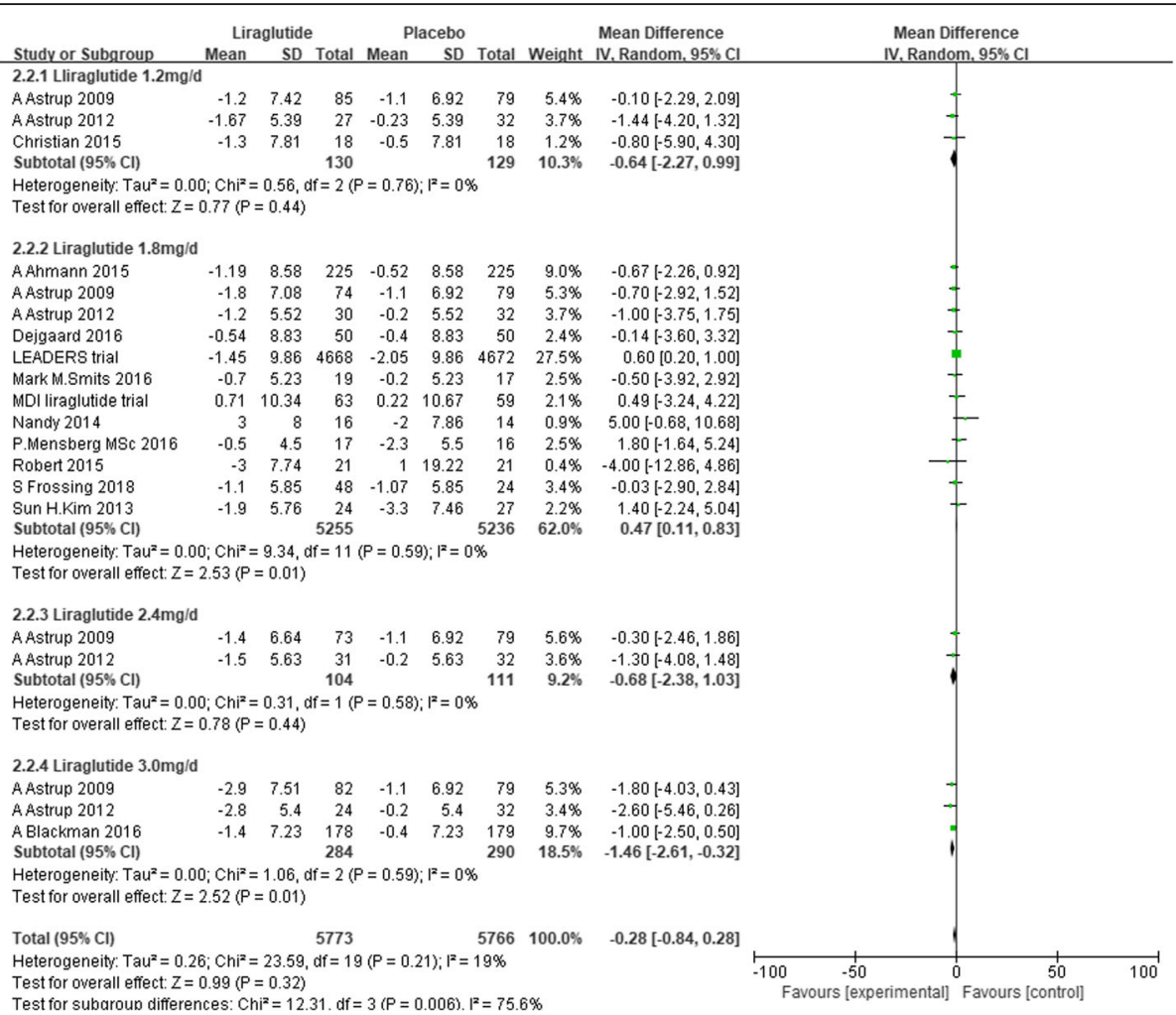

Fig. 8 The forest plot of DBP in subgroup analysis defined by the dose of liraglutide (random- effects model)

evidence that GLP-1RAs mediate sodium excretion and diuresis in order to lower blood pressure [64-66].

Intensive control of glucose levels and blood pressure is currently the mainstay of both prevention and treatment of diabetic nephropathy. The LEADER trial showed that liraglutide-induced benefits on renal outcome could be due to improvements in renal risk factors, such as renal haemodynamics [67]. GLP-1RAs may induce renoprotection by inhibiting renal tubular sodium reabsorption, facilitating water excretion [64-66] and decreasing glomerular pressure. A pooled analysis of four studies showed that DPP-4 inhibitors led to a significant reduction in albuminuria in patients with type 2 diabetes [68].

All trials found that liraglutide significantly reduced body weight compared with placebo [29, 31, 36-51]. The reduction in SBP partly contributes to the reduction in body weight. However, on the basis of the SBP and weight profiles over time, the reduction in SBP may not be fully explained by the reduction in body weight [37]. Based on the time course of SBP and weight reductions, the reduction in SBP occurred before substantial weight loss [47]. A meta-analysis showed that significant reductions in SBP were observed as early as 2 weeks after initiation of liraglutide treatment and could be observed before any significant weight loss occurred [68].

\section{Strengths and limitations}

The aim of this meta-analysis was to discuss the influence of liraglutide on blood pressure in individuals with or without abnormal glucose metabolism by searching high-quality RCTs to provide reliable evidence for clinical practice. However, some limitations should be noted. First, Robert SA et al. did not provide the number of people who were lost to follow-up or withdrew and the reasons these participants were lost follow-up or withdrew. Four RCTs did not give a clear method of random sequence and allocation concealment [38-41]. These factors increased the bias risk of the studies included. Second, because of the limitation of sample size in stratifications treated with liraglutide $2.4 \mathrm{mg} / \mathrm{d}$ and $3.0 \mathrm{mg} / \mathrm{d}$, the subgroup analysis might be inaccurate. Third, there was a lack of clinical trials on the efficacy of liraglutide on blood pressure in patients with and without hypertension.

\section{Conclusions}

In this meta-analysis, $18 \mathrm{RCTs}$ were included to explore the effect of liraglutide on blood pressure. The results showed that compared with placebo, liraglutide significantly reduced SBP. At doses of liraglutide up to $3.0 \mathrm{mg} / \mathrm{d}$, the reduction in DBP was significant. At present, liraglutide is widely recognised to have a 


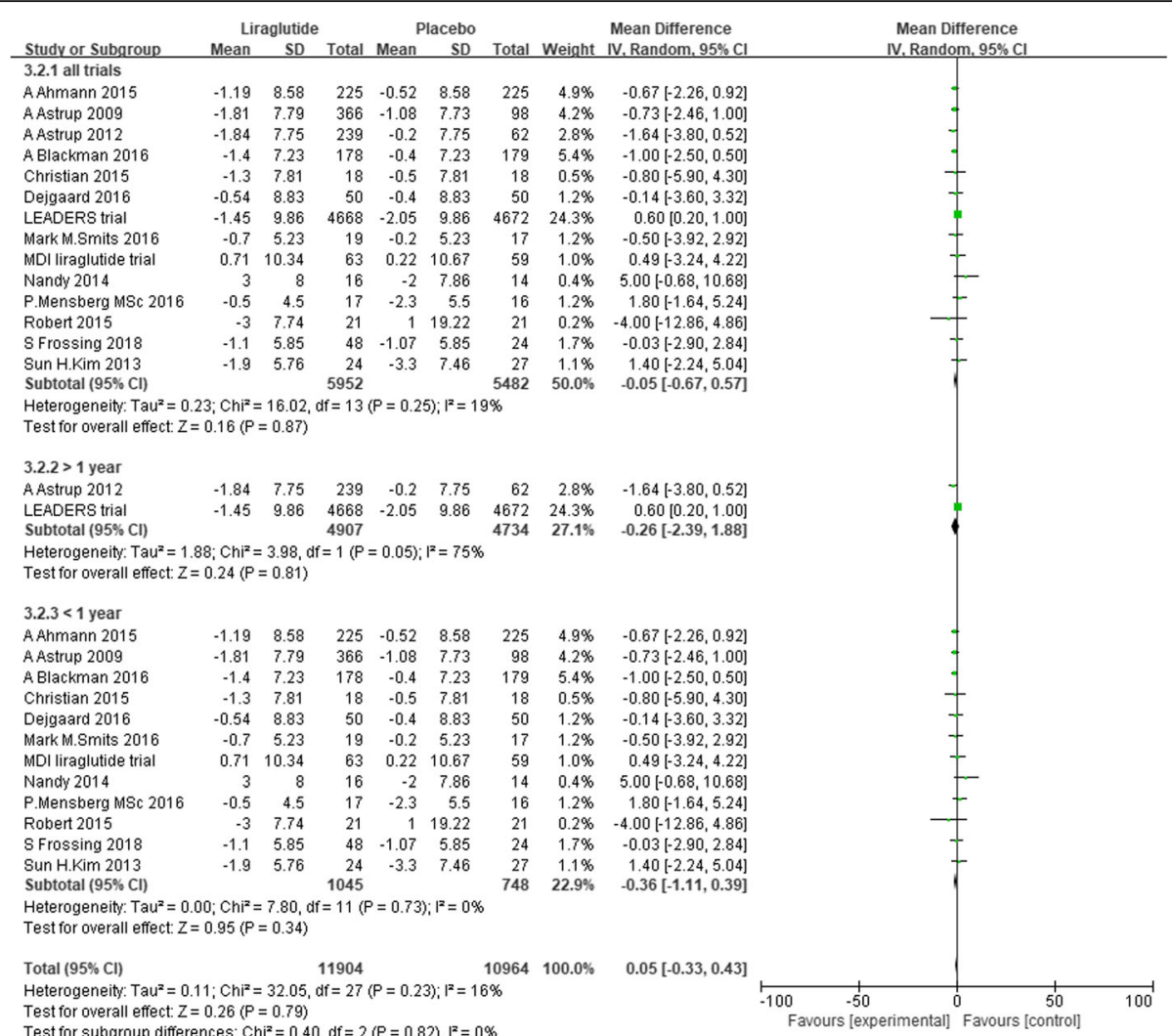

Fig. 9 The forest plot of DBP in subgroup analysis defined by the duration of intervention (random-effects model)

beneficial effect on glucose reduction, weight loss and protection of $\beta$-cells. With the efficacy on blood pressure, the application of liraglutide in clinical practice may be broadened in the future. More clinical trials are needed to investigate the further effect of liraglutide on blood pressure.

\section{Abbreviations}

ACE inhibitors: Angiotensin-converting enzyme inhibitors; ADA: American Diabetes Association; ARBs: Angiotensin receptor blockers; BMI: Body mass index; BP: Blood pressure; DBP: Diastolic blood pressure; DM: Diabetes mellitus; DPP-4: Dipeptidyl peptidase-4; GLP-1RAs: Glucagon-like peptide-1 receptor agonists; IDF: International Diabetes Federation; NA: Not applicable; OAH: Oral antihyperglycaemics; RCTs: Randomised controlled trials; SBP: Systolic blood pressure; TZDs: Thiazolidinediones

\section{Acknowledgements}

Not applicable.

\section{Funding}

No funding was obtained for this study.

\section{Availability of data and materials}

The datasets used and analysed during the current study available from the corresponding author on reasonable request.

\section{Authors' contributions}

JD conducted the study. XZ and KH performed the study selection, and $M Z$ performed the process when XZ and Kun Huang had disagreement. XZ analyzed the data and was a major contributor in writing the manuscript. All authors read and approved the final manuscript.
Ethics approval and consent to participate

Not applicable.

\section{Consent for publication}

Not applicable.

\section{Competing interests}

The authors declare that they have no competing interests.

\section{Publisher's Note}

Springer Nature remains neutral with regard to jurisdictional claims in published maps and institutional affiliations.

Received: 9 August 2018 Accepted: 27 December 2018

Published online: 07 January 2019

\section{References}

1. International Diabetes Federation. Five questions on the IDF diabetes atlas. Diabetes Res Clin Pract. 2013;102(2):147-8

2. Bommer C, Sagalova V, Heesemann E, et al. Global economic burden of diabetes in adults: projection from 2015 to 2030. Diabetes Care. 2018;41(5): $963-70$.

3. American Diabetes Association. 9. Cardiovascular Disease and Risk Management: Standards of Medical Care in Diabetes-2018. Diabetes Care. 2018;41(Suppl 1):S86-S104.

4. Hansson L, Zanchetti A, Carruthers SG, et al. Effects of intensive blood pressure lowering and low-dose aspirinin patient with hypertension: principal results of Hypertension Optimal Treatment (HOT) randomised trial. HOT Study Group. Lancet. 1998:351:1755-62.

5. UK Prospective Diabetes Study Group. Tight blood pressure control and rick of macrovascular and microvascular complications in type 2 diabetes: UKPDS 38. BMJ. 1998:317:703-13. 
6. Turner RC, Milns $\mathrm{H}$, Neil HA, et al. Risk factors for coronary artery disease in non-insulin dependent diabetes mellitus: United Kingdom prospective diabetes study (UKPDS: 23). BMJ. 1998;316:823-8.

7. Estacio RO, Schrier RW. Antihypertensive therapy in type 2 diabetes: implications of the appropriate blood pressure control in diabetes (ABCD) trial. Am J Cardiol. 1998:82:9R-14R.

8. Patel A, ADVANCE Collaborative Group, MacMahon S, et al. Effects of a fixed combination of perindopril and indapamide on macrovascular and microvascular outcomes in patients with type 2 diabetes mellitus (the ADVANCE trial): A randomised cotrolled trial. Lancet. 2007;370:829-40.

9. Brady EM, Davies MJ, Gray LJ, et al. A randomized controlled trial comparing the GLP-1 receptor agonist liraglutide to a sulphonylurea as add on to metformin in patients with established type 2 diabetes during Ramadan: the treat 4 Ramadan Tiral. Diabetes Obes Metab. 2014;16(6):527-36.

10. Nauck M, Frid A, Hermansen $K$, et al. Long-term efficacy and safety comparison of liraglutide, glimepiride and placebo, all in combination with metformin in type 2diabetes: 2-year results from the LEAD-2 study. Diabetes Obes Metab. 2013;15(3):204-12.

11. Lee WC, Dekoven M, Bouchard J, Massoudi M, Langer J. Improved real-word glycaemic outcome with liraglutide versus other incretin-based therapies in type 2 diabetes. Diabetes Obes Metab. 2014;16(9):819-26.

12. Yang $W$, Chen $L$, Ji Q, et al. Liraglutide provides similar glycaemic control as glimepiride (both in combination with metformin) and reduces body weight and systolic blood pressure in Asian population with type 2 diabetes from China, South Korea and India: a 16-week, randomized, double-blind, active control trial. Diabetes Obes Metab. 2011;13(1):81-8.

13. Seino Y, Rasmussen MF, Nishida T, Kaku K. Efficacy and safety of the once-daily human GLP-1 analogue liraglutide vs glibenclamide monotherapy in Japanese patients with type 2 diabetes. Curr Med Res Opin. 2010;26(5):1013-22.

14. Abdul-Ghani MA, Williams K, Kanat M, Altuntas Y, DeFronzo RA. Insulin vs GLP-1 analogues in poorly controlled Type 2 diabetic subjects on oral therapy: a meta-analysis. J Endocrinal Invest. 2013;36:168-73.

15. Tanaka K, Saisho Y, Kawai T, et al. Efficacy and safety of liraglutide monotherapy compared with metformin in Japanese overweight/obese patients with type 2 diabetes. Endocr J. 2015;62(5):399-409.

16. Ma Z, Chen R, Liu Y, Yu P, Chen L. Effect of liraglutide vs. NPH in combination with metformin on blood glucose fluctuations assessed using continuous glucose monitoring in patients with newly diagnosed type 2 diabetes. Int J Clin Pharmacol Ther. 2015;53(11):933-9.

17. Garcia Diaz E, Guaqnozzi D, Gutierrez V, et al. Effect of incretin therapies compared to pioglitazone and gliclazide in non-alcoholic fatty liver disease in diabetic patients not controlled on metformin alone: an observational, pilot study. Endocrinol Nutr. 2016;63(5):194-201.

18. Seino Y, Rasmussen MF, Clasuson P, Kaku K. The once-daily human glucagon-like peptide-1 analog, liraglutide, improves $\beta$-cell function in Japanese patients with type 2 diabetes. Diabetes Investig. 2012;3(4):388-95.

19. Madsbad S, Schmitz O, Ranstam J, Jakobsen G, Matthews DR, NN2211-1310 International Study Group. Improved glycemic control with no weight increase in patients with type 2 diabetes after once-daily treatment with the longacting glucagon-like peptide 1 analog liraglutide (NN2211): a 12-week, doubleblind, randomized, controlled trial. Diabetes Care. 2004;27(6):1335-42.

20. Bays H, Pi-Sunyer X, Hemminqsson JU, Claudius B, Jensen CB, Van Gaal L. Liraglutide 3.0 mg for weight management: weight-loss dependent and independent effects. Curr Med Res Opin. 2017;33(2):225-9.

21. Lane W, Weinrib S, Rappaport J, Hale C. The effect of addition of liraglutide to high-dose intensive insulin therapy: a randomized prospective trial. Diabetes Obes Metab. 2014;16(9):827-32.

22. Davies MJ, Bain SC, Atkin SL, et al. Efficacy and safety of Liraglutide versus placebo as add-on to glucose-lowering therapy in patients with type 2 diabetes and moderate renal impairment (LIRA-RENAL): a randomized clinical trial. Diabetes Care. 2016;39(2):222-30.

23. Retnakaran $\mathrm{R}$, Kramer CK, Choi H, Swaminathan B, Zinman B. Liraglutide and the preservation of pancreatic $\beta$-cell function in early type 2 diabetes: the LIBRA trial. Diabetes Care. 2014;37(12):3270-8.

24. Kondo $Y$, Satoh S, Osada UN, Terauchi $Y$. Early liraglutide treatment improves $\beta$-cell function in patients with type 2 diabetes: a retrospective cohort study. Endocr J. 2015;62(11):971-80.

25. Sun F, Yu K, Wu S, et al. Cardiovascular safety and glycemic control of glucagon-like peptide-1 receptor agonists for type 2 diabetes mellitus: a pairwise and network meta-analysis. Diabetes Res Clin Pract. 2012; 98(3):386-95
26. Chudleigh RA, Bain S. Cardiovascular safety of liraglutide for the treatment of type 2 diabetes. Expert Opin Drug Saf. 2017;16(5):627-35.

27. Viswanathan $P$, Chaudhuri A, Bhatia R, Al-Atrash F, Mohanty P, Dandona P. Exentide therapy in obese patients with type 2 diabetes mellitus treated with insulin. Endocr Pract. 2007;13:444-50.

28. Rosso GT, Labate AM, Giandalia A, et al. Twelve-month treatment with Liraglutide ameliorates visceral adiposity index and common cardiovascular risk factors in type 2 diabetes outpatients. J Endocrinol Investig. 2015;38(1):81-9.

29. Astrup A, Rossner $S$, Van Gaal L, et al. Effects of liraglutide in the treatment of obesity: a randomized, double-blind, placebo-controlled study. Lancet. 2009;374:1606-16.

30. Marso SP, Poulter NR, Nisseen SE, et al. Design of the liraglutide effect and action in diabetes: Evaluation of cardiovascular outcome results (LEADER) trial. Am Heart J. 2013;166(5):823-30.e5.

31. Marso SP, Daniels GH, Brown-Frandsen K, et al. Liraglutide and cardiovascular outcomes in type 2 diabetes. N Engl J Med. 2016;28:311-22.

32. Hiramatsu T, Ozeki A, Asai K, Saka M, Hobo A, Furuta S. Liraglutide improves glycemic and blood pressure control and ameliorates progression of left ventricular hypertrophy in patients with type 2 diabetes mellitus on peritoneal dialysis. Ther Apher Dial. 2015;19(6):598-605.

33. Robinson LE, Holt TA, Rees K, Randeva HS, O'Hare JP. Effects of exenatide and liraglutide on heart rate, blood pressure and body weight: systematic review and meta-analysis. BMJ Open. 2013;3(1).

34. Wang B, Zhong J, Lin H, et al. Blood pressure-lowering effects of GLP-1 receptor agonists exenatide and liraglutide: a meta-analysis of clinical trial. Diabetes Obes Metab. 2013;15(8):737-49.

35. Higgins JPT, Green S (editors). Cochrane Handbook for Systematic Reviews of Interventions Version 5.1.0 (2011). Available: http://handbook-5-1. cochrane.org/

36. Marre M, Shaw J, Brandle M, et al. Liraglutide, a once-daily human GLP-1 analogue, added to a sulphonylurea over 26 weeks produces greater improvements in glycaemic and weight control compared with adding rosiglitazone or placebo in subjects with type 2 diabetes (LEAD-1 SU). Diabet Med. 2009;26:268-78.

37. Nauck M, Frid A, Hermansen $\mathrm{K}$, et al. Efficacy and safety comparison of liraglutide, glimepiride, and placebo, all in combination with metformin, in type 2 diabetes: the LEAD (liraglutide effect and action in diabetes)-2 study. Diabetes Care. 2009;32:84-90.

38. Frandsen CS, Dejgaard TF, Holst JJ, Andersen HU, Thorsteinsson B, Madsbad S. Twelve-week treatment with Liraglutide as add-on to insulin in Normal-weight patients with poorly controlled type 1 diabetes: a randomized, placebo-controlled. Double-Blinded Parallel Study. Diabetes Care. 2015;38(12):2250-7.

39. Mensberg P, Nyby S, Jorgensen PG, et al. Near-normalization of glycaemic control with glucagon-like peptide-1 receptor agonist treatment combined with exercise in patient with type 2 diabetes. Diabetes Obes Metab. 2017; 19(2):172-80.

40. Robert SA, Rohana AG, Shah SA, Chinna K, Wan Mohamud WN, Kamaruddin NA. Improvement in binge eating in non-diabetic obese individuals after 3 months of treatment with liraglutide - a pilot study. Obes Res Clin Pract. 2015;9(3):301-4.

41. Kim SH, Abbasi F, Lamendola C, et al. Benefits of liraglutide treatment in overweight and obese older individual with prediabetes. Diabetes Care. 2013;36(10):3276-82.

42. Ahmann A, Rodbard HW, Rosenstock J, et al. Efficacy and safety of liraglutide versus placebo added to basal insulin analogues (with or without metformin) in patients with type 2 diabetes: a randomized, placebocontrolled trial. Diabetes Obes Metab. 2015;17:1056-64.

43. Astrup A, Carraro R, Finer N, et al. Safety, tolerability and sustained weight loss over 2 years with the once-daily human GLP-1 analog, liraglutide. Int J Obes. 2012;36:843-54

44. Blackman A, Foster GD, Zammit G, et al. Effect of liraglutide 3.0 mg in individuals with obesity and moderate or severe obstructive sleep apnea: the SCALE Sleep Apnea randomized clinical trial. Int J Obes. 2016:40:1310-9.

45. Dejgaard TF, Frandsen CS, Hansen TS, et al. Efficacy and safety of liraglutide for overweight adult patients with type 1 diabetes and insufficient glycaemic control (lira-1): a randomised, double-blind, placebo-controlled trial. Lancet Diabetes Endocinol. 2016;4(3):221-32.

46. Zinman B, Gerich J, Buse JB, et al. Efficacy and safety of the human glucagon-like peptide-1 analog liraglutide in combination with metformin 
and thiazolidinedione in patients with type 2 diabetes (LEAD-4 met+TZD). Diabetes Care. 2009;32(7):1224-30.

47. Russell-Jones D, Vaag A, Schmitz O, et al. Liraglutide vs insulin glargine and placebo in combination with metformin and sulfonylurea trerapy in type 2 diabetes mellitus (LEAD-5 met+SU): a randomized controlled trial. Diabetologia. 2009:52(10):2046-55.

48. Smits MM, Tonneijck L, Muskiet MH, et al. GLP-1-based therapies have no microvascular effects in type 2 diabetes mellitus: an acute and 12-week randomized, double-blind. Placebo-Controlled Trial. Arteioscler Thromb Vasc Biol. 2016;36(10):2125-32

49. Lind M, Hirsch IB, Tuomilehto J, et al. Liraglutide in people treated for type 2 diabetes with multiple daily insulin injections: randomized clinical trial (MDI Liraglutide trial). BMJ. 2015;351:h5364.

50. Nandy D, Johnson C, Basu R, et al. The effect of liraglutide on endothelial function in patients with type 2 diabetes. Diab Vasc Dis Res. 2014;1 1(6):419-30.

51. Frossing S, Mylander M, Kistorp C, Skouby SO, Faber J. Effect of liraglutide on atrial natriuretic peptide, adrenomedullin, and copeptin in PCOS. Endocr Connect. 2018;7(1):115-23.

52. Wang T, Gou Z, Wang F, Ma M, Zhai SD. Comparison of GLP-1 analogues versus sitaglipitin in the management of type 2 diabetes: systematic review and meta-analysis of head-to-head studies. PLoS One. 2014;9(8):e103798.

53. Gu J, Menq X, Guo Y, et al. The efficacy and safety of liraglutide added to metformin in patients with diabetes: a meta-analysis of randomized controlled trials. Sci Rep. 2016;6:32714.

54. Fonseca VA, Devries JH, Henry RR, Donsmark M, Thomsen HF, Plutzky J. Reductions in systolic blood pressure with liraglutide in patients with type 2 diabetes: insights from a patient-level pooled analysis of six randomized clinical trials. J Diabetes Complicat. 2014;28(3):399-405.

55. Sun F, Wu S, Guo S, et al. Impact of GLP-1 receptor agonists on blood pressure, heart rate and hypertension among patients with type 2 diabetes: a systematic review and network meta-analysis. Diabetes Res Clin Pract. 2015;110(1):26-37.

56. Henry RR, Buse JB, Sesti G, et al. Efficacy of antihyperglycemic therapies and the influence of baseline hemoglobin $\mathrm{A}(1 \mathrm{C})$ : a meta-analysis of the liraglutide development program. Endocr Pract. 2011;17(6):906-13.

57. Plutzky J, Garber A, Falahati A, Toft AD, Poulter NR. Reductions in lipids and $\mathrm{CV}$ risk markers in patients with type 2 diabetes treated with liraglutide: a meta-analysis. Can J Diabetes. 2009;33(3):209-10.

58. UK Prospective Diabetes Study Group. Tight blood pressure control and risk of macrovascular and microvascular complications in type 2 diabetes. BMJ. 1998;317(7160):703-13.

59. Patel A, ADVANCE Collaborative Group, MacMahon S, Chalmers J, et al. Effects of a fixed combination of perindopril and indapamide on macrovascular and microvascular outcomes in patients with type 2 diabetes mellitus (the ADVANCE trial): a randomised controlled trial. Lancet. 2007; 370(9590):829-40.

60. Krisai P, Aeschbacher S, Schoen T, Bossard M, et al. Glucagon-like peptide-1 and blood pressure in young and healthy adults from the general population. Hypertension. 2015;65(2):306-12

61. Ban K, Noyan-Ashraf MH, Hoefer J, Bolz SS, et al. Cardioprotective and vasodilatory actions of glucagon-like peptide 1 receptor are mediated through both glucagon-like peptide 1 receptor-dependent and -independent pathways. Circulation. 2008:117(18):2340-50.

62. Basu A, Charkoudian N, Schrage W, Rizza RA, et al. Beneficial effects of GLP1 on endothelial function in humans: dampening by glyburide but not by glimepiride. Am J Physiol Endocrinol Metab. 2007;293(5):E1289-95.

63. Gaspari T, Liu H, Welungoda I, Hu Y, et al. A GLP-1 receptor agonist liraglutide inhibits endothelial cell dysfunction and vascular adhesion molecule expression in an ApoE-/- mouse model. Diab Vasc Dis Res. 2011; 8(2):117-24.

64. Thomson SC, Kashkouli A, Singh P. Glucagon-like peptide-1 receptor stimulation increases GFR and suppresses proximal reabsorption in the rat. Am J Physiol Renal Physiol. 2013;304(2):F137-44

65. Yu M, Moreno C, Hoagland KM, Dahly A, et al. Antihypertensive effect of glucagon-like peptide 1 in dahl salt-sensitive rats. J Hypertens. 2003;21 (6):1125-35.

66. Gutzwiller JP, Hruz P, Huber AR, Hamel C, et al. Glucagon-like peptide-1 is involved in sodium and water homeostasis in humans. Digestion. 2006; 73(2-3):142-50

67. Groop PH, Cooper ME, Perkovic V, Emser A, et al. Linagliptin lowers albuminuria on top of recommended standard treatment in patients with type 2 diabetes and renal dysfunction. Diabetes Care. 2013;36(11):3460-8.
68. Montanya E, Sesti G. A review of efficacy and safety data regarding the use of liraglutide, a once-daily human glucagon-like peptide 1 analogue, in the treatment of type 2 diabetes mellitus. Clin Ther. 2009;31(11):2472-88.

69. Pickering TG, Hall JE, Appel LJ, et al. Recommendations for blood pressure measurement in humans and experimental animals: part 1: blood pressure measurement in humans: a statement for professionals from the Subcommittee of Professional and Public Education of the American Heart Association Council on high blood pressure research. Hypertension. 2005; 45(1):142-61.

70. Chobanian AV, Bakris GL, Black HR, et al. The seventh report of the joint National Committee on prevention, detection, evaluation, and treatment of high blood pressure: the JNC 7 report. JAMA. 2003;289(19):2560-72.

71. Smits MM, Tonneijck L, Muskiet MH, et al. Cardiovascular, renal and gastrointestinal effects of incretin-based therapies: an acute and 12-week randomised, double-blind, placebo-controlled, mechanistic intervention trial in type 2 diabetes. BMJ Open. 2015;5(11):e009579.

72. Nylander M, Frøssing S, Kistorp C, et al. Liraglutide in polycystic ovary syndrome: a randomized trial, investigating effects on thrombogenic potential. Endocr Connect. 2017;6(2):89-99.

\section{Ready to submit your research? Choose BMC and benefit from:}

- fast, convenient online submission

- thorough peer review by experienced researchers in your field

- rapid publication on acceptance

- support for research data, including large and complex data types

- gold Open Access which fosters wider collaboration and increased citations

- maximum visibility for your research: over $100 \mathrm{M}$ website views per year

At BMC, research is always in progress.

Learn more biomedcentral.com/submissions 